\title{
Anti-inflammatory and antioxidant potential capacities of AD-MSCs and BM-MSCs in suppressing pancreatic $\beta$-cells auto-immunity and apoptosis in rats with T1DM induced model
}

\author{
SHADY G. EL-SAWAH ${ }^{1, *}$; FAYEZ ALTHOBAITI ${ }^{2}$; HANAN M. RASHWAN ${ }^{1}$; AdIL ALDHAHRANI ${ }^{3}$; MARWA A. ABDEL-DAYEM ${ }^{4}$;
} Eman FAYAD ${ }^{2}$; Rehab M. AMEN ${ }^{5}$; El Shaimaa SHABANA ${ }^{6}$; Ehab I. EL-HALlOUS 7

${ }^{1}$ Zoology Department, Faculty of Science, Arish University, North Sinai, Egypt

${ }^{2}$ Biotechnology Department, Faculty of Science, Taif University, Taif, Saudi Arabia

${ }^{3}$ Clinical Laboratory Science Department, Turabah University College, Taif University, Taif, Saudi Arabia

${ }^{4}$ Department of Pharmacology and Biochemistry, Faculty of Pharmacy, Horus University-Egypt, New Damietta, Egypt

5 Biology Department, College of Science, University of Bisha, Bisha, Saudi Arabia

${ }^{6}$ Fellow of Biochemistry, Genetic Unit, Children Hospital, Faculty of Medicine, Mansoura University, Dakahlia Governorate, Egypt

${ }^{7}$ Biology Department, Faculty of Science, Taif University, Taif, Saudi Arabia

Key words: Antioxidants, Apoptosis, Diabetes, Inflammation, Stem cells

\begin{abstract}
Since Type 1 diabetes (T1DM) occurs when $\beta$-cells mass is reduced to less than $20 \%$ of the normal level due to autoimmune destruction of cells resulting in the inability to secrete insulin, preservation or replenishment of the functional $\beta$-cells mass has become a major therapeutic focus for this diabetic type treatment. Thus, this 4 -week work plan was designed to determine which mesenchymal stem cells (MSCs) type is more appropriate to alleviate pancreatic hazards resulting from diabetes induction; via tracking a comparative study between MSCs derived from adipose tissue (AD-MSCs) and from bone marrow (BM-MSCs) in management of T1DM considering their immunomodulatory, anti-apoptotic and antioxidative roles. Rats were divided randomly into 4 groups; control, STZdiabetic (D), D+AD-MSCs, and D+BM-MSCs groups. Both stem cells types in this study were allogenic. Herein, both oxidative stress and antioxidant markers were evaluated using colorimetric analysis, while inflammatory, immune and apoptotic markers were assessed through flow cytometric analysis. Results showed that diabetic rats treated with either AD-MSCs or BM-MSCs exhibited marked pancreatic antioxidant and anti-inflammatory activities that were able to initiate pancreatic immunomodulation and reducing $\beta$-cells apoptotic death, thus, help to restore their normal insulin secretion and hypoglycemic abilities. However, AD-MSCs injection was shown to be superior as a pancreatic regenerative tool in overcoming diabetes; owing to their marked antioxidant, anti-inflammatory, immunomodulatory, and anti-apoptotic characteristics over BM-MSCs treatment.
\end{abstract}

\section{List of Abbreviations}

AD-MSCs: Adipose-derived mesenchymal stem cells

AGEs: $\quad$ Advanced glycation end products

BM-MSCs: Bone marrow-derived mesenchymal stem cells

CAT:

CD:

Catalase

D: Cluster of differentiation

DM:

DMEM: Dulbecco's modified Eagle's medium

*Address correspondence to: Shady G. El-Sawah, dr.shadygamal83@gmail.com

Received: 08 June 2021; Accepted: 10 August 2021
FBG:

FBS:

GPx:

GRd:

GSH:

GST:

HbAlc:

$\mathrm{H}_{2} \mathrm{O}_{2}$ :

HO-1:

IPCs:

MDA:

MSCs:

PBS:
Fasting blood glucose

Fetal bovine serum

Glutathione peroxidase

Glutathione reductase

Glutathione

Glutathione-S-transferase

glycosylated hemoglobin

Hydrogen peroxide

Heme-oxygenase 1

Insulin producing cells

Malondialdehyde

Mesenchymal stem cells

Phosphate-buffered saline cited. 


$\begin{array}{ll}\text { ROS: } & \text { Reactive oxygen species } \\ \text { SEM: } & \text { Standard error of mean } \\ \text { SOD: } & \text { Superoxide dismutase } \\ \text { SPSS: } & \text { Statistical Package for Social Scientists } \\ \text { STZ: } & \text { Streptozotocin } \\ \text { T1DM: } & \text { Type } 1 \text { diabetes mellitus } \\ \text { TAC: } & \text { Total antioxidant capacity } \\ \text { T-reg: } & \text { regulatory T-cells } \\ \text { XO: } & \text { Xanthine oxidase }\end{array}$

\section{Introduction}

Genetic autoimmune irreversible destruction of pancreatic insulin-producing $\beta$-cells due to a progressive defective immune regulation was considered the hallmark of Type 1 diabetes mellitus (T1DM); which counts for approximately $5 \%$ to $10 \%$ of diabetic patients. The prevalence of T1DM is $0.1 \%-0.5 \%$ among the general population worldwide with an incidence of $30-50$ per 100,000 people, associated with an annual $3 \%$ increasing rate. Millions of patients, often children, suffer from T1DM; as it is more common in peripubertal boys, usually noticed for the first time in young ages of 5-7 years, that not associated with obesity or family history (Thakkar et al., 2017; Boddu et al., 2020; Erendor et al., 2021). Because of being insulin-dependent, it is more dangerous than Type II and is commonly complicated with ketosis. It is generally lethal unless treated with daily exogenous insulin. However, exogenous control of insulin dosage cannot compensate for the sensitive adjustment normally made by $\beta$-cells (Gibbons and Freeman, 2020; Williams et al., 2020). Furthermore, insufficient insulin doses could lead to extreme hyperglycemia or diabetic ketoacidosis, while in some cases, intensive insulin therapy may further result in hypoglycemic shock (Takahashi et al., 2019).

Evidence indicated that auto-reactive $\mathrm{CD} 4^{+}$and $\mathrm{CD} 8^{+} \mathrm{T}$ lymphocytes could mediate the destruction of $70-100 \%$ of the insulin-producing $\beta$-cells; via releasing huge amounts of cytokines (such as interleukin-2 (IL-2) and $\gamma$-interferon $(\mathrm{IFN}-\gamma)$ triggering an inflammatory response that leads to progressive irreversible insulin-producing islets $\beta$-cells' damage; eventually results in their dysfunction and nearly absolute insulin secretion deficiency, causing hyperglycemia (Boddu et al., 2020; Zhong et al., 2020). Hence, addressing the inflammatory response, besides $\beta$-cell mass replenish, may provide an opportunity for T1DM therapy, with the aim of controlling or arresting the progression of $\beta$-cells destruction and restoring normal glycemic control and immune hemostasis.

In the last decade, the cell-based therapies have offered a new paradigm in the management of T1DM for creating an unlimited source of insulin-producing cells (IPCs), repairing $\beta$ cell function, modulating metabolism, and improving immune dysfunction. In this regard, owing to their immunosuppressive properties, there has been much interest revolving around mesenchymal stem cells (MSCs) as an emerging strategy for the treatment of autoimmune diseases for their therapeutic potential, especially in regenerative medicine. Since new $\beta$-cells generation is an important target in T1DM treatment; thus, MSCs usage could be the ideal choice for this disease therapy. This could be attributed to their capabilities in modulating immune and inflammatory cells, restoring islet function, endogenous islet cells protection, induction of islet cell regeneration and differentiation into IPCs; followed by marked restoration of $\beta$-cell mass and significant hypoglycemia (Amer et al., 2018; Ullah et al., 2019); via functioning as a potent source of various cytokines and growth factors with powerful immune-modulating, angiogenic, and anti-apoptotic effects which could support the residual $\beta$-cells regeneration and participating in the suppression of the autoimmune reaction against $\beta$-cells (Boháčová and Holáň, 2018; Takahashi et al., 2019). These factors are able to manage the immune system activity by suppressing T-cells activation, proliferation and maturation; inhibiting naïve and memory $\mathrm{T}$-cells response; and upregulating the production of regulatory T-cells (T-regs); while such regulation needs to be licensed by inflammation (Qi et al., 2017; Takahashi et al., 2019; Ullah et al., 2019).

However, there are various types of stem cells with different potency and sources; thus, the therapeutic effects and utility were different (Qi et al., 2019). Interestingly, most studies have examined MSCs derived from bone marrow (BM-MSCs) and adipose tissue (AD-MSCs) for their easy isolation in large quantities, marked abilities to retain their immunomodulatory characteristics, and high amounts of extracellular matrix components production potentiality (Bagno et al., 2018). Surprisingly, IPCs differentiated from either AD-MSCs or BM-MSCs injection could obviously lower glucose and $\mathrm{HbA1c}$ serum levels and increase both Cpeptide and insulin release in diabetic rats (Gabr et al., 2017; El-Kholy et al. (2018) and in diabetic mice (Kono et al., 2014) as well as in diabetic patients (Thakkar et al., 2015); confirming MSCs hypoglycemic activity. Zang et al. (2017) also reported that BM-MSCs showed a powerful glycemic control indicated by the $50 \%$ decline in insulin requirements; through restoring islet function, endogenous islet cells protection, induction of islet cell regeneration and differentiation into IPCs; followed by marked restoration of $\beta$-cell mass and significant hypoglycemia in STZ-diabetic mice.

Chandra et al. (2009) first induced AD-MSCs into IPCs using murine epididymal (mE)-ASCs of Swiss albino mice. After 10 days of culture with differentiation cocktails, ADMSCs progressively differentiated into cells expressing insulin in a glucose-dependent manner. These IPCs transplanted into experimental diabetic mice bring about normoglycemia within 2 weeks. Compared to undifferentiated AD-MSCs, IPCs group mice showed a better therapeutic effect in improving glucose levels by increasing circulating insulin levels and ameliorating metabolic parameters including IL-6. In this regard, Amer et al. (2018) also found that STZdiabetic rats received IPCs differentiated from AD-MSCs; showed an apparent islet cells proliferation and regeneration that leads to a marked C-peptide increase accompanied by insulin secretion elevation; in glucose-dependent manner. Besides, other animal experiments have demonstrated that AD-MSC infusion could improve hyperglycemia through the recovery of islet $\beta$ cells, reduction of inflammation, and improvement of insulin sensitivity ( $\mathrm{Hu}$ et al., 2015; Wang et al., 2018). It is also worth noting that some mechanism 
exploration provide the potential of AD-MSC clinical application (Shree and Bhonde, 2017; Xie et al., 2017). Similar results in diabetic subjects were reported by Chen et al. (2020) regarding AD-MSCs $\left(1 \times 10^{6}\right.$ cells/rat) injection, and by El-Kholy et al. (2018); El-Sawah et al. (2020) regarding BM-MSCs $\left(1 \times 10^{6}\right.$ cell/rat $)$ injection; compared to the diabetic untreated rats.

Interestingly, it has been demonstrated that MSCs could directly suppress T-cells activation/proliferation while inducing its apoptosis by expressing nitric oxide (NO), indoleamine 2,3, dioxygenase (IDO), programmed death-ligand 1 (PD-L1), or Fas ligand. Hence, the starting hypothesis is that MSCs hypoglycemic effect could be considered as an indirect effect of secretion of immunomodulators, which prevent T-cells from eliciting pancreatic $\beta$-cell destruction in T1DM (Zhou et al., 2016; Sordia et al., 2017). Additionally, MSCs transplantation was found to alleviated tissue inflammatory infiltration of lymphocytes and macrophages by lowering expression of IL- $1 \beta$, IL- 6 , IL-8, MCP-1, TGF- $\beta$, TNF- $\alpha$, and other pro-inflammatory cytokines in diabetic rats (Chandravanshi and Bhonde, 2017; Hamza et al., 2017).

In regard to $\beta$-cells death in T1DM, Chandravanshi and Bhonde (2017) study showed that after $48 \mathrm{~h}$ of MSCs transplantation, islet cells exhibited higher viability and reduced apoptosis. It was suggested that MSCs may have shown diverse mechanisms of action including harboring anti-apoptotic and pro-proliferative properties via secreting various potent paracrine cytoprotective, angiogenic, antiinflammatory, and growth factors; including vascular endothelial growth factor (VEGF), hepatocyte growth factor (HGF), fibroblast growth factor (FGF) and prostaglandin E2 (PGE2), and insulin growth factor-1 (IGF-1). Such growth factors could function as trophic mediators which can regulate the local microenvironment of the damaged tissue, reduce inflammation, improve the immune defense system, promote tissue regeneration and revascularization, and may also play an important role in the enhancement of angiogenesis, stimulation of cell proliferation, and the attenuation of cell death responses in diabetes (Sordia et al., 2017; Takahashi et al., 2019; Aminzadeh et al., 2020).

Taken together, this study focuses on exploring the best choice of MSCs therapies in T1DM via seeking to be the first to compare head-to-head of AD-MSCs and BM-MSCs outcomes as an innovative strategy to cure T1DM; through investigating their antioxidant, immunomodulating, and anti-inflammatory potencies in alleviating and suppressing the resultant pancreatic oxidative stress and apoptotic status; using a model of streptozotocin-induced diabetic rats.

\section{Materials and Methods}

\section{Chemicals}

Streptozotocin (STZ) and culture media constituents of both BM-MSCs and AD-MSCs were purchased from Sigma Aldrich Co. (St. Louis, Mo 6, USA); and were of a pure chemical gradient.

\section{Biochemical assays}

Serum glucose concentration was estimated by Trinder (1969) method using SPINREACT diagnostics kit, Spain. Insulin measurement occurred by ELISA kit purchased from Boehringer Mannheim, Germany, according to the method of Flier et al. (1976) using Boehringer Analyzer ES 300. C-peptide measurement occurred by enzyme immunoassay (EIA) kit purchased from Bio Vision, USA, according to the method of Flier et al. (1976). Glycosylated hemoglobin (HbAlc) and advanced glycation end products (AGEs), were estimated according to the methods of Gonen and Rubenstein (1978) by using kits obtained from Teco Diagnostics, USA. Bio Diagnostic Company (Egypt) kits were used in estimating tissue levels of some oxidative stress markers [Xanthine oxidase (XO) and Reactive oxygen species (ROS) according to Young (2001) methods, Malondialdehyde (MDA) according to Ohkawa et al. (1982)] in addition to many antioxidant markers [Catalase (CAT) according to Bock et al. (1980), Glutathione-Stransferase (GST) according to Habig et al. (1974), Superoxide dismutase (SOD) according to Nishikimi et al. (1972), Glutathione (GSH) according to Prins and Loose (1969), Heme-oxygenase 1 (HO-1) according to Gonen and Rubenstein (1978) and Total antioxidant capacity (TAC) according to Koracevic et al. (2001)]. However, CRP level was determined quantitatively in serum using CRPSPINREACT diagnostics kit, Spain according to Vaishnavi (1996). All according to the instructions of the supplier.

\section{Flow cytometric analysis}

Pancreatic inflammatory markers (TNF- $\alpha$, TGF- $\beta$, CD95 ${ }^{+}$, IL-6), immunity markers $\left(\mathrm{CD}^{+}, \mathrm{CD}^{+}\right)$, and apoptotic markers (annexin V, P53, caspase-3, Bcl-2, and G0/G1 \%), in addition to CD44, CD73, CD90, CD45, CD11b and CD31 MSCs surface markers \% (for characterization of the isolated BM-MSCs and AD-MSCs phenotyping), were determined via Sigma Aldrich Company (St. Louis, Mo 6, USA) kits through flow cytometric analysis. A fresh tissue specimen was washed with isotonic tris EDTA buffer, dissolved in $250 \mathrm{ml}$ of distilled water at $7.5 \mathrm{pH}$ (using $1 \mathrm{~N} \mathrm{HCl}$ ), and centrifuged for $10 \mathrm{~min}$ at $1800 \mathrm{rpm}$, then aspire supernatant. Cells are fixed in ice-cold $96-100 \%$ ethanol ( $1 \mathrm{ml}$ for each sample), then stored in the refrigerator. Regarding cells staining, the fluorochrome is directly linked to the primary antibody (Phycoerythrin (PE) conjugate). Cell suspension adjusted (10 cell $/ \mathrm{mL}$ ) with PBS/BSA buffer $\mathrm{pH}$ 7.4. The cell suspension was Aliquoted into test tubes $(100 \mu \mathrm{L}$ each), then a $7 \mu \mathrm{L}$ antibody was added for each tube, mixed well, and incubated for $30 \mathrm{~min}$ at room temperature. Then, cells were washed with $2 \mathrm{~mL}$ of PBS/BSA and centrifuged for $5 \mathrm{~min}$ at $4000 \mathrm{rpm}$. However, the resulting supernatant was discarded and cells were resuspended in $0.2 \mathrm{~mL}$ of PBS/BSA (Tribukait et al., 1975). Finally, data were acquired by flow cytometry using FACS Caliber flow cytometer (Becton Dickinson, Sunnyvale, CA, USA), equipped with a compact air cooked low power $15 \mathrm{~m}$ watt argon iron laser beam $(488 \mathrm{~nm})$. The average evaluated cells per specimen were 10.000. Dean and Jett's computer program for mathematical analysis is used to obtain the DNA histograms (Dean and Jett, 1974).

\section{$B M-M S C s$ and AD-MSCs preparation}

Fresh bone marrow and subcutaneous adipose tissues have been used to isolate allograft BM-MSCs and AD-MSCs 
respectively were obtained from (6-8 weeks) male Wistar rats. To prepare BM-MSCs, each end of the femur and tibia was cut to expose the marrow cavity, then washed three times with phosphate-buffered saline (PBS). Fresh bone marrow was collected and centrifuged at $2000 \mathrm{rpm}$ for $10 \mathrm{~min}$. Pelleted cells were suspended in Dulbecco's modified Eagle's medium (DMEM) supplemented with $10 \%$ fetal bovine serum (FBS) and $100 \mathrm{U} / \mathrm{mL}$ penicillin with $100 \mu \mathrm{g} / \mathrm{mL}$ streptomycin as an antibiotic at $37^{\circ} \mathrm{C}$ in a $5 \% \mathrm{CO}_{2}$ atmospheric state with $95 \%$ humidity, then centrifuged at $2000 \mathrm{rpm}$ for $10 \mathrm{~min}$ (Hamza et al., 2017). On the other hand, 1-2 mg fresh rats' subcutaneous adipose tissues (epididymal fat) were harvested by lipoaspiration, minced, washed extensively three times in PBS and incubated into a digestion solution containing $0.075 \%$ collagenase type I (prepared in PBS) at $37^{\circ}$ for 3 hours, then centrifuged for 10 minutes at $2000 \mathrm{rpm}$. After discarding the supernatant, cells were collected as a pellet and suspended in DMEM (10\% FBS, $2 \mathrm{mM}$ L-glutamine, and $100 \mathrm{U} / \mathrm{ml}$ penicillin with $100 \mu \mathrm{g} / \mathrm{mL}$ streptomycin as an antibiotic) at $37^{\circ} \mathrm{C}$ in $5 \% \mathrm{CO}_{2}$ with $95 \%$ humidity (Chen et al., 2020). The growth mediums of both MSCs types were changed every 3 days, and non-adherent cells were removed. All MSCs used in this study were from passages 3-4 and transferred chilled for transplantation within $2 \mathrm{~h}$.

\section{BM-MSCs and AD-MSCs characterization}

The inverted microscope has been used to perform both BM-MSCs and AD-MSCs morphological characterization for confirming their identity. Moreover, the stemness of cultured cells should be confirmed by positive and negative surface markers (CD11b, CD34, CD45, CD73, CD90 and CD105) by flow cytometry, Figs. $1 \mathrm{~A} \& 1 \mathrm{~B}$, to confirm retaining of their phenotype before performing the animal study; according to the minimal criteria defined by ISCT.

\section{Experimental animals and maintenance}

The experiment was conducted in accordance with the guidelines of the Animal Ethics Committee of Faculty of Science, Arish University, North Sinai, Egypt. Male albino allogenic Wistar rats (6-8 weeks, 100-120 g) were obtained from the laboratory animal facility of the National Research Center, Dokki, Giza, Egypt. Rats kept at room temperature $\left(22 \pm 2^{\circ} \mathrm{C}\right)$ with humidity of $50 \pm 5 \%, 12 / 12$-hours light/ dark cycle and were fed standard pellet chow (El-Nasr Chemical Co., Cairo, Egypt), where food and water were allowed ad libitum. After two weeks of acclimatization before dietary manipulation, four equals groups rat groups $(\mathrm{n}=6)$ were randomly selected from 24 rats.

\section{Diabetes induction}

A single STZ solution dose $(45 \mathrm{mg} / \mathrm{kg}$ dissolved in citrate buffer, $\mathrm{pH}$ 4.6) were injected intraperitoneally in overnight fasting rats; while control rats received the vehicle alone. Animals were allowed to drink 5\% glucose solution overnight to overcome drug-induced hypoglycemia. Diabetes was confirmed 3 days after induction via detecting the level of blood glucose from the tail vein; using Glukotest of diagnosis glucose level by ACCU-CHEKGo apparatus (Roche Company, Germany Only rats with fasting blood glucose (FBG) above $250 \mathrm{mg} / \mathrm{dl}$ were considered diabetic
(Kodidela et al., 2020). The experiential protocol was continued for 4 consecutive weeks.

\section{Experimental design}

- Control group: Injected intraperitoneally with a single dose of sodium citrate buffer ( $\mathrm{pH} 4.5)$.

- Diabetic (D) untreated group: Injected intraperitoneally with a single dose of STZ (45 mg/kg bw) dissolved in sodium citrate buffer ( $\mathrm{pH} 4.5)$.

- Diabetic AD-MSCs treated group: Injected intravenously with a single dose of AD-MSCs $\left(1 \times 10^{6}\right.$ cell/rat $)$, following diabetes induction confirmation.

- Diabetic BM-MSCs treated group: Injected intravenously with a single dose of BM-MSCs $\left(1 \times 10^{6}\right.$ cell/rat $)$, following diabetes induction confirmation.

\section{Samples collection}

After 4 weeks experimentation period, overnight fasted rats were anesthetized using diethyl ether before being dissected and blood samples were immediately withdrawn directly from the heart. For glycosylated hemoglobin (HbAlc) assessment, a few droplets of blood samples were placed in clean heparinized tubes. On the other hand, the remaining blood samples were collected in clean non-heparinized centrifuge tubes, then let to stand for $15 \mathrm{~min}$, and centrifuged for $15 \mathrm{~min}$ at $3000 \mathrm{rpm}$. Blood sera were carefully separated, labeled, and kept at $-20^{\circ} \mathrm{C}$ for subsequent biochemical analysis. Meanwhile, pancreas specimens were removed and cleaned with saline solution, where an appropriate part was weighed and homogenized in cold distilled water forming $10 \%(\mathrm{w} / \mathrm{v})$ homogenate, then labeled and kept at $-20^{\circ} \mathrm{C}$ for later biochemical estimations. While another part was stored in $10 \%$ formalin solution for subsequent histopathological examination. However, the remnant parts were labeled and kept at $-80^{\circ} \mathrm{C}$ for subsequent flowcytometric analysis.

\section{Histochemical examination}

Rats were autopsied and samples of the pancreas were cut into around $1 \mathrm{~cm}$ thickness, immersed in $10 \%$ neutral buffer formalin for fixation, processed routinely to be embedded in paraffin to perform samples blocks to be sectioned via microtome producing 3-5 $\mu \mathrm{m}$ thickness sections that were mounted on labeled glass slides for further Hematoxylin and Eosin staining using (Leica Auto Stainer) automatic instrument. Afterward, samples' slides were examined via a light microscope (Suvarna et al., 2013).

\section{Statistical analysis}

Obtained data were statistically evaluated with ANOVA followed by Post-Hoc Tukey multiple range tests using Statistical Package for the Social Sciences (SPSS/17.5 software version) for Windows. All the results were expressed as the Mean \pm SEM $(n=6)$. The significance between groups was considered at the $P \leq 0.05$.

\section{Results}

Table 1 showed marked serum glucose and HbAlc elevation coupled with significant insulin and C-peptide 

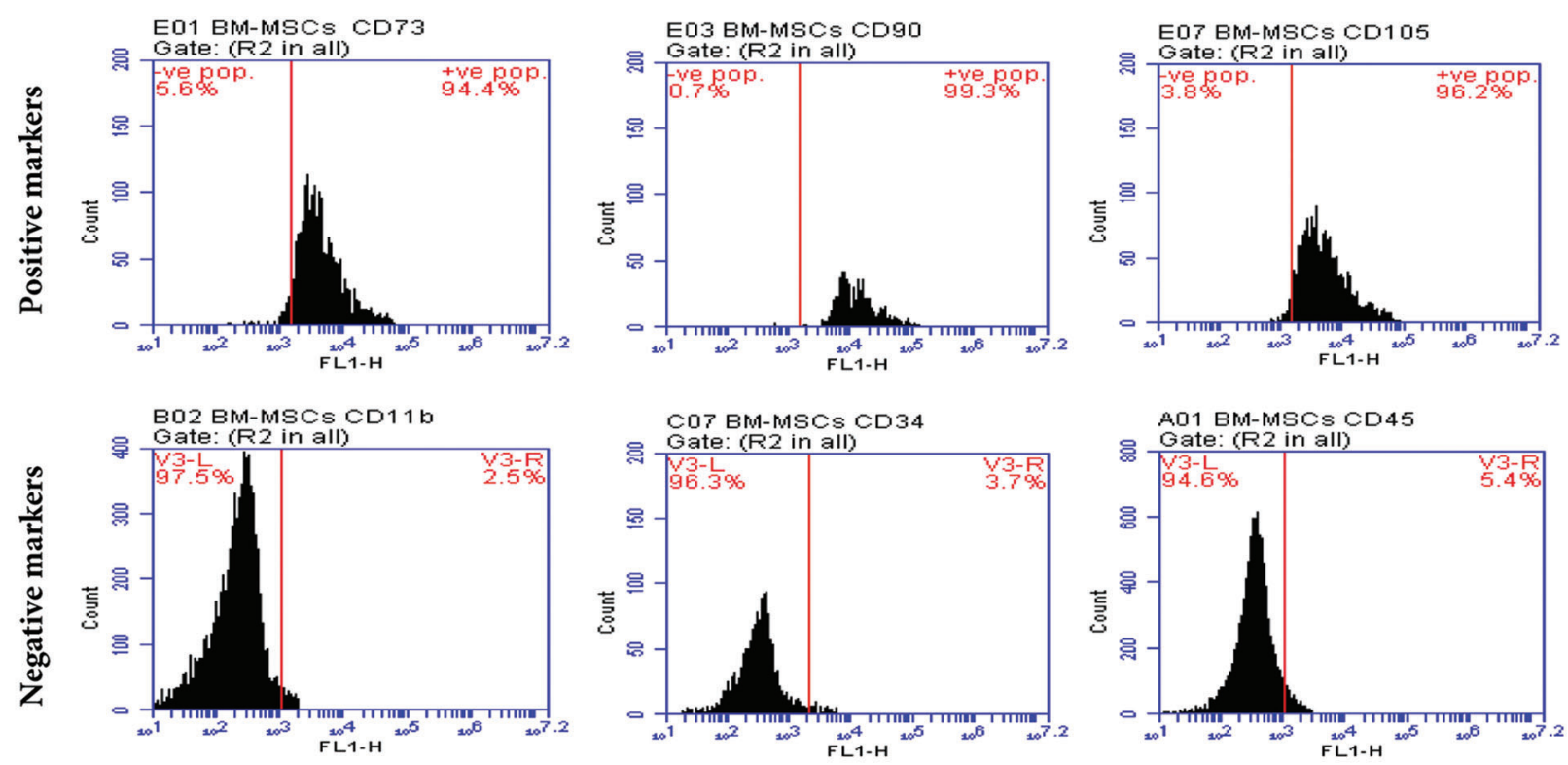

(A)
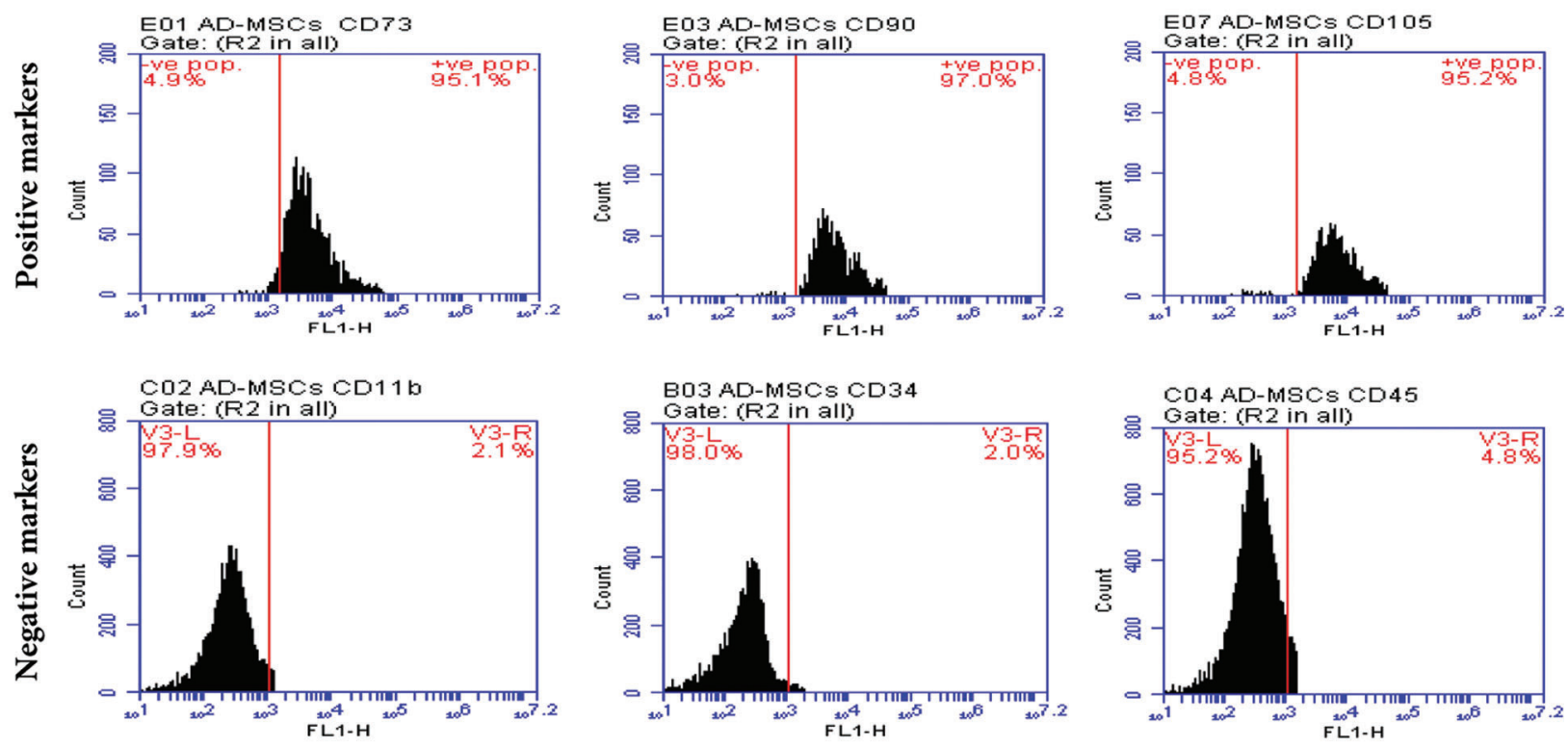

(B)

FIGURE 1. (A\&B): BM MSCs and AD MSCs characterization, respectively. Fig. 1A: BM-MSCs positive surface markers (CD 73: 94.4\%, CD 90: 99.3\%, CD 105: 96.2\%), and BM-MSCs negative surface markers (CD 11b: 2.5\%, CD 34: 3.7\%, CD 45: 5.4\%). Fig. 1B: AD-MSCs positive surface markers (CD 73: 95.1\%, CD 90: 97.0\%, CD 105: 95.2\%), and AD-MSCs negative surface markers (CD 11b: 2.1\%, CD 34: 2.0\%, CD 45: 4.8\%).

TABLE 1

Serum glucose, insulin, C-peptide and HbA1c levels

\begin{tabular}{lllll}
\hline & Control & Diabetic (D) & D+AD-MSCs & D+BM-MSCs \\
\hline Glucose (mg/100 ml) & $93.91 \pm 4.42$ & $405.40 \pm 16.46^{\mathbf{a}}$ & $96.75 \pm 5.70^{\mathbf{b}}$ & $160.50 \pm 5.22^{\mathbf{a b c}}$ \\
Insulin ( $\mu \mathrm{IU} / \mathbf{m l})$ & $17.15 \pm 0.66$ & $8.02 \pm 0.33^{\mathbf{a}}$ & $16.90 \pm 0.34^{\mathbf{b}}$ & $14.32 \pm 0.57^{\mathbf{a b c}}$ \\
C-peptide (ng/ml) & $0.84 \pm 0.03$ & $0.30 \pm 0.03^{\mathbf{a}}$ & $0.81 \pm 0.01^{\mathbf{b}}$ & $0.75 \pm 0.02^{\mathbf{a b c}}$ \\
HbA1c (\%) & $2.95 \pm 0.11$ & $4.90 \pm 0.20^{\mathbf{a}}$ & $2.98 \pm 0.14^{\mathbf{b}}$ & $3.29 \pm 0.10^{\mathbf{a b c}}$ \\
\hline
\end{tabular}

Note: Values expressed as mean \pm SEM $(n=6){ }^{\mathbf{a}, \mathbf{b}}$ and ${ }^{\mathbf{c}}$ are Significant differences $(P \leq 0.05)$ comparing to control, diabetic and diabetic AD-MSCs treated groups, respectively.

levels decline in the diabetic group; compared to control. Regarding both MSCs-treated groups, all measured parameters of the diabetic rats revealed an obvious enhancement relative to diabetics; although values of BM-MSCs were still significantly variable relative to control. However, data of diabetic rats injected with 
AD-MSCs detected a marked hypoglycemic superiority when compared to those of BM-MSCs.

Table 2 illustrates that the diabetic group exhibited significant increases in pancreatic oxidative stress markers (MDA, ROS, and $\mathrm{XO}$ ) levels coupled with a marked decline in all antioxidant markers (GSH, SOD, CAT, GST, TAC, and HO-1) levels in addition to pancreatic viable cells (G0/ G1) \%; when compared to the control group. However, present results revealed that diabetic rats treated with either AD-MSCs or BM-MSCs showed a marked decrease in oxidative stress markers, while a significant increase in both antioxidant markers levels and G0/G1 \%; when compared to the diabetic group. On the other hand, AD-MSCs cleared non-significant changes in all tested parameters compared to control group; in contrast to BM-MSCs values which were still significantly variable. Interestingly, all results of diabetic rats treated with AD-MSCs recorded a much more enhancement than BM-MSCs treatment.

Table 3 and Figs. 2A-2D illustrate that the diabetic group exhibited significant increases in pancreatic inflammatory markers (CRP, TNF- $\alpha$, TGF- $\beta$, CD95, and IL-6) \%; when compared to the control group. However, present results revealed that diabetic rats treated with either $\mathrm{AD}-\mathrm{MSC}$ or BM-MSCs showed a marked decrease in these inflammatory markers \%; when compared to the diabetic group. On the other hand, AD-MSCs cleared non-significant changes in all tested parameters compared to control group; in contrast to BM-MSCs, values were still significantly higher than normal values. Interestingly, $\mathrm{AD}-\mathrm{MSC}$ administration recorded a much more anti-inflammatory efficacy than BM-MSCs treatment in diabetic rats, where, $2 \mathrm{~A}, 2 \mathrm{~B}, 2 \mathrm{C}$ and $2 \mathrm{D}$, represents TNF- $\alpha$, TGF- $\beta$, CD95 ${ }^{+}$, and IL- $6 \%$, respectively.

Summarized data in the Table 4 and Figs. $3 \mathrm{~A}$ and $3 \mathrm{~B}$ indicated a marked elevation in both pancreatic immune parameters $\%$ in the diabetic group; regarding normal control one. On the other hand, relative to the diabetic group; both MSCs-treated groups' results showed a significant enhancement in tested parameters. Surprisingly, obtained results of the diabetic rats injected with AD-MSCs displayed an obvious improvement variation in the pancreatic immune condition, compared to those treated with BM-MSCs, where, Figs. 3A and 3B, represents CD4 \& CD8\%, respectively.

Table 5 and Figs. 4A-4D obtained results revealed a marked apoptotic status development in pancreatic cells of diabetic rats; as suggested via the significant increases in many apoptotic markers (annexin V, P53, and caspase 3\%) accompanied by a significant decrease in both anti-apoptotic marker (Bcl-2\%) and pancreatic viable cells count (G0/G1 $\%)$; in regard to control rats. On the contrary, Both MSCs treated groups' tested indicators clearly demonstrated a significant improvement; when compared to the diabetic untreated group. Notably, diabetic rats injected with $\mathrm{AD}$ MSCs recorded a great amelioration in the overall pancreatic immune environment; comparing to BM-MSCs treated rats, where, Figs. $4 \mathrm{~A}, 4 \mathrm{~B}, 4 \mathrm{C}$ and $4 \mathrm{D}$, represents annexin V, P53, caspase 3 \& Bcl-2\%, respectively.

Fig. 5 Photomicrograph of $\mathrm{H} \& \mathrm{E}$-stained pancreatic tissue displaying a typical histological image of islets of Langerhans.

- (A) control, group showed normal intact features of (IL) islets of Langerhans, (AC) acinar cells, and (CT) connective tissue septa.

- (B) STZ-treated group displayed evident degeneration illustrated in islets shrinkage ${ }^{*}$ ), necrotic areas (white arrowhead), pyknotic nucleus (black arrows), and congested blood vessel.

- (C) AD-MSCs treated diabetic group showed marked structural restoration.

- (D) BM-MSCs treated diabetic group showed marked structural restoration except for the presence of limited apoptotic nuclei (black arrowhead).

\section{Discussion}

Concomitant with our results, course STZ administration was found to selectively targets and kills pancreatic $\beta$ cells, causing a huge serum glucose and $\mathrm{HbAlc}$ levels increase, coupled with a marked C-peptide and insulin levels decline, and subsequent prolonged hyperglycemia; regarding control subjects;

\section{TABLE 2}

Pancreatic oxidative stress, antioxidant markers levels \& viable cells (G0/G1) \%

\begin{tabular}{lllll}
\hline & Control & Diabetic (D) & D+AD-MSCs & D+BM-MSCs \\
\hline MDA (n mol/g) & $10.40 \pm 0.43$ & $30.33 \pm 1.05$ & $10.65 \pm 1.03^{\mathbf{b}}$ & $15.50 \pm 1.76^{\mathbf{a b c}}$ \\
ROS (n mol/g) & $0.79 \pm 0.03$ & $2.12 \pm 0.08^{\mathbf{a}}$ & $0.80 \pm 0.03^{\mathbf{b}}$ & $1.02 \pm 0.02^{\mathbf{a b c}}$ \\
XO (nmol/ml) & $21.50 \pm 1.03$ & $50.00 \pm 2.67^{\mathbf{a}}$ & $22.25 \pm 1.08^{\mathbf{b}}$ & $29.50 \pm 1.10^{\mathbf{a b c}}$ \\
GSH (mg/gm) & $53.00 \pm 2.05$ & $21.30 \pm 1.34^{\mathbf{a}}$ & $50.50 \pm 2.64^{\mathbf{b}}$ & $39.06 \pm 2.87^{\mathbf{a b c}}$ \\
SOD (u/gm) & $10.22 \pm 0.32$ & $4.50 \pm 0.13^{\mathbf{a}}$ & $10.11 \pm 0.43^{\mathbf{b}}$ & $8.60 \pm 0.43^{\mathbf{a b c}}$ \\
CAT (u/gm) & $0.60 \pm 0.04$ & $0.32 \pm 0.03^{\mathbf{a}}$ & $0.62 \pm 0.03^{\mathbf{b}}$ & $0.49 \pm 0.02^{\mathbf{a b c}}$ \\
GST (Mmol/gm) & $6.30 \pm 0.21$ & $2.70 \pm 0.16^{\mathbf{a}}$ & $6.22 \pm 0.22^{\mathbf{b}}$ & $4.50 \pm 0.24^{\mathbf{a b c}}$ \\
TAC (mg/gm) & $1.89 \pm 0.09$ & $0.53 \pm 0.03^{\mathbf{a}}$ & $1.85 \pm 0.07^{\mathbf{b}}$ & $1.40 \pm 0.06^{\mathbf{a b c}}$ \\
HO-1 (P mol/mg) & $309.00 \pm 13.42$ & $110.00 \pm 4.26^{\mathbf{a}}$ & $304.00 \pm 11.23^{\mathbf{b}}$ & $235.00 \pm 13.09^{\mathbf{a b c}}$ \\
G0/G1 \% & $93.50 \pm 2.23$ & $55.40 \pm 1.37^{\mathbf{a}}$ & $92.50 \pm 2.73^{\mathbf{b}}$ & $75.00 \pm 2.22^{\mathbf{a b c}}$ \\
\hline
\end{tabular}

Note: Values expressed as mean \pm SEM $(n=6){ }^{\mathbf{a}, \mathbf{b}}$ and ${ }^{\mathbf{c}}$ are Significant differences $(P \leq 0.05)$ comparing to control, diabetic and diabetic AD-MSCs treated groups respectively. 

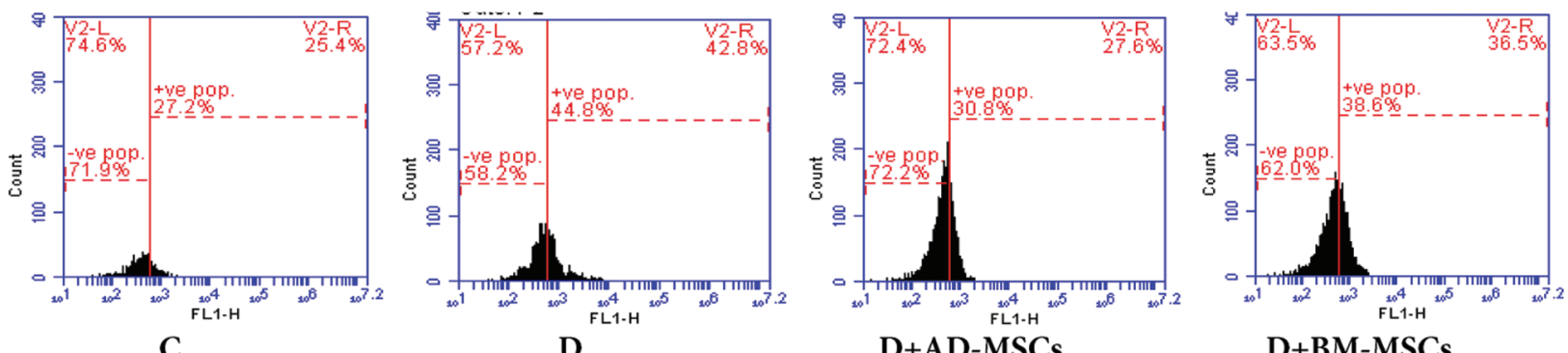

(A)
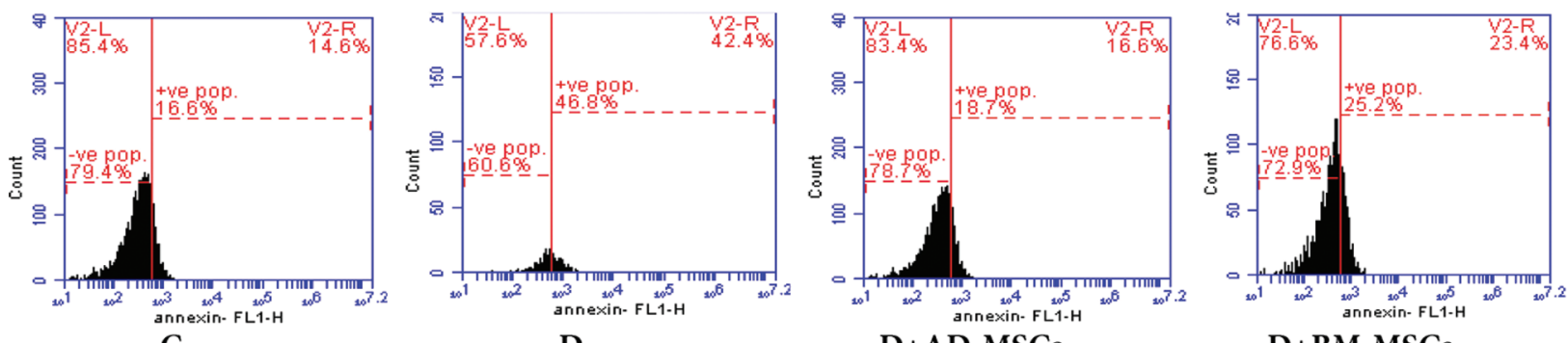

(B)
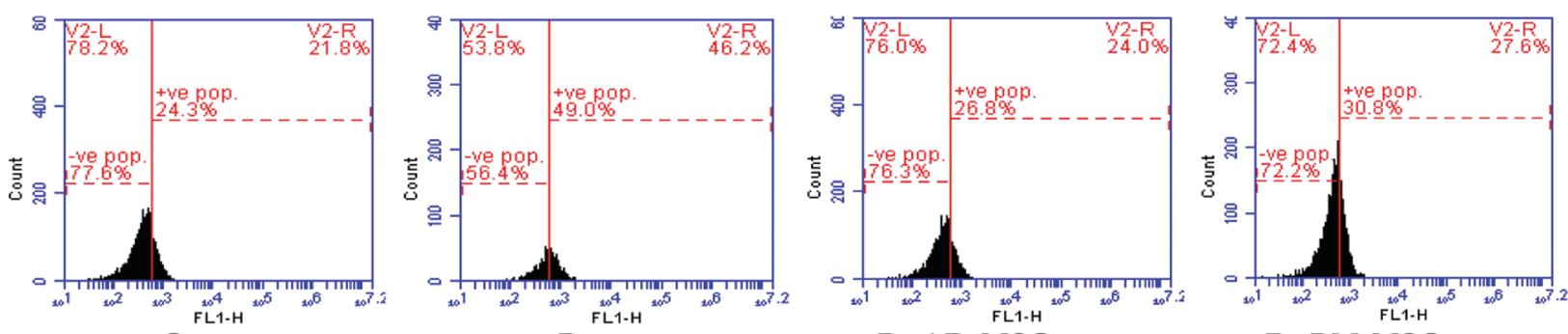

C

D

D+AD-MSCs

D+BM-MSCs

(C)
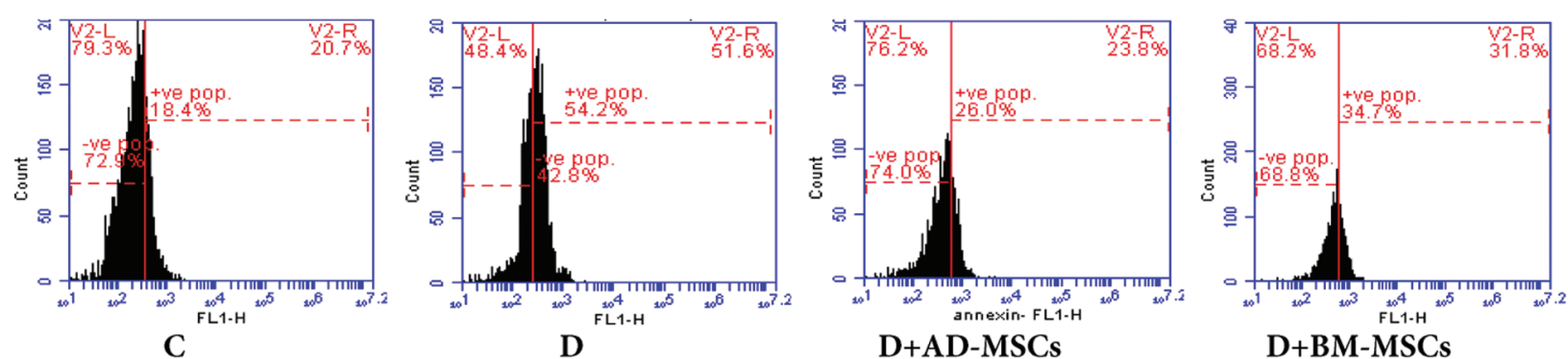

(D)

FIGURE 2. (A-D): Pancreatic inflammatory markers (CRP, TNF- $\alpha$, TGF- $\beta$, CD95, and IL-6) \%, respectively.

Results revealed that diabetic rats treated with either AD-MSCs or BM-MSCs showed a marked decrease in these inflammatory markers \%; when compared to the diabetic group. On the other hand, AD-MSCs cleared non-significant changes in all tested parameters compared to the control group; in contrast to BM-MSCs, values were still significantly higher than normal values.

inducing an experimental model of T1DM (Amer et al., 2018; Samaha et al., 2020). Such intracellular hyperglycemia was supposed to cause damage to the vascular endothelium through various mechanisms including-(i) activation of four biochemical pathways, namely the Polyol pathway, protein kinase $\mathrm{C}$ (PKC) pathway, AGEs pathway and hexosamine pathway; all of which commutes glucose and its intermediates leading to overproduction of ROS, (ii) progression of oxidative stress (iii) dysregulation of growth factors and cytokines, (iv) epigenetic changes which concern the changes in DNA as a response to intracellular changes, (v) abnormalities in non-coding RNAs, specifically microRNAs, and (vi) inflammation and cell death of the pancreatic $\beta$-islets (Jamshidi et al., 2018; Laddha and Kulkarni, 2019; Paul et al., 2020). In particular, these high levels of AGEs also disrupt the defense mechanisms and assist in the destruction of $\beta$-cells through activating different kinases and NADPH oxidase leading to ROS increased production; which further promotes the synthesis of more AGEs; thereby triggering cell-damaging 
TABLE 3

Pancreatic CRP, TNF- $\alpha$, TGF- $\beta$, CD95 and IL-6 levels

\begin{tabular}{lllll}
\hline & Control & Diabetic (D) & D+AD-MSCs & D+BM-MSCs \\
\hline CRP (g/dl) & $3.65 \pm 0.13$ & $18.10 \pm 0.65^{\mathbf{a}}$ & $4.00 \pm 0.34^{\mathbf{b}}$ & $7.50 \pm 0.32^{\mathbf{a b c}}$ \\
TNF-a (\%) & $27.76 \pm 1.76$ & $44.56 \pm 2.23^{\mathbf{a}}$ & $30.60 \pm 1.83^{\mathbf{b}}$ & $38.50 \pm 1.28^{\mathbf{a b c}}$ \\
TGF- $\beta$ (\%) & $16.50 \pm 0.82$ & $48.76 \pm 2.23^{\mathbf{a}}$ & $18.25 \pm 1.82^{\mathbf{b}}$ & $25.60 \pm 1.06^{\mathbf{a b c}}$ \\
CD95 $^{+}$(\%) & $24.40 \pm 1.62$ & $49.40 \pm 2.98^{\mathbf{a}}$ & $28.60 \pm 1.45^{\mathbf{b}}$ & $32.60 \pm 1.68^{\mathbf{a b c}}$ \\
IL-6 (\%) $^{\text {abc }}$ & $18.55 \pm 1.76$ & $54.00 \pm 2.34^{\mathbf{a}}$ & $26.55 \pm 1.38^{\mathbf{b}}$ & $34.10 \pm 1.72^{\mathbf{a b c}}$ \\
\hline
\end{tabular}

Note: Values expressed as mean \pm SEM $(n=6){ }^{\mathbf{a}, \mathbf{b}}$ and ${ }^{\mathbf{c}}$ are Significant differences $(P \leq 0.05)$ comparing to control, diabetic and diabetic AD-MSCs treated groups respectively.

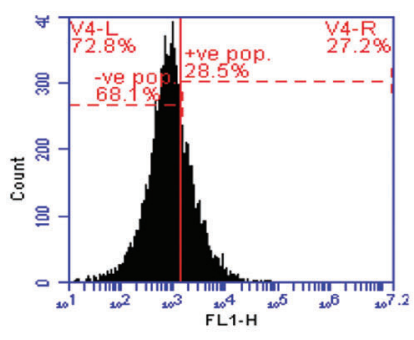

C

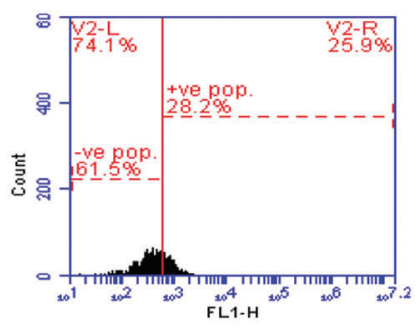

C

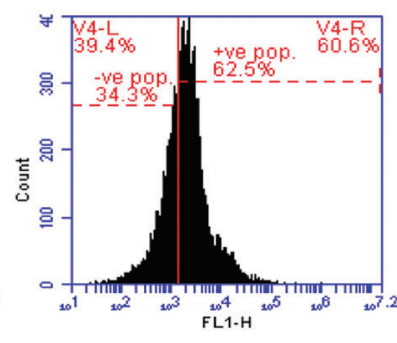

D

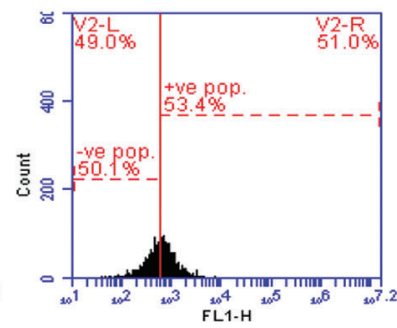

D

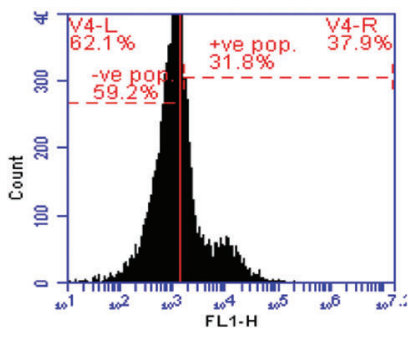

D+AD-MSCs

(A)

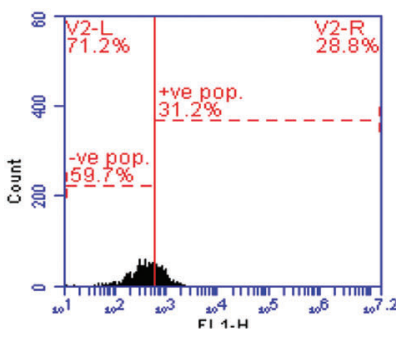

D+AD-MSCs

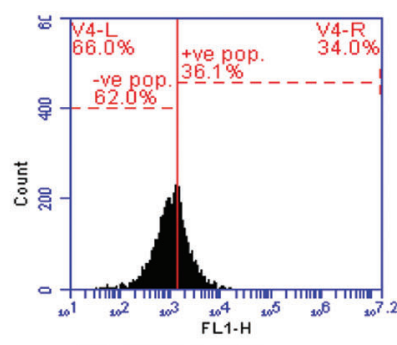

D+BM-MSCs

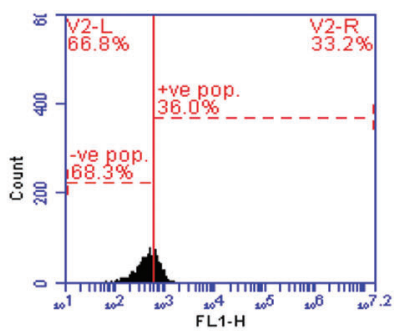

D+BM-MSCs

(B)

FIGURE 3. (A\&B): Pancreatic CD4 \& CD8\%, respectively.

Data indicated a marked elevation in both pancreatic immune parameters \% in the diabetic group; regarding normal control one. On the other hand, relative to the diabetic group; both MSCs-treated groups' results showed a significant enhancement in tested parameters.

TABLE 4

Pancreatic T-Helper CD $4^{+}$and T-Cytotoxic CD $8^{+}(\%)$

\begin{tabular}{|c|c|c|c|c|}
\hline & Control & Diabetic (D) & D+AD-MSC & D+BM-MSCs \\
\hline T-Helper CD $4^{+}(\%)$ & $28.95 \pm 1.20$ & $62.23 \pm 3.12^{\mathbf{a}}$ & $31.12 \pm 1.52^{\mathbf{b}}$ & $36.55 \pm 1.36^{\mathbf{a b c}}$ \\
\hline T-Cytotoxic CD $8^{+}(\%)$ & $29.00 \pm 1.42$ & $53.50 \pm 2.87^{\mathbf{a}}$ & $31.40 \pm 1.27^{\mathbf{b}}$ & $36.90 \pm 1.82^{\mathbf{a b c}}$ \\
\hline
\end{tabular}

Note: Values expressed as mean \pm SEM $(n=6){ }^{\mathbf{a}, \mathbf{b}}$ and ${ }^{\mathbf{c}}$ are Significant differences $(P \leq 0.05)$ comparing to control, diabetic and diabetic AD-MSCs treated groups, respectively.

mechanisms (Peng et al., 2018). However, oxidative stress injury and elevated ROS and MDA production were recognized as the major etiological factor in the development of diabetes; which might be a reflection of the decreased antioxidant capability of the defensive systems and/or glucose oxidation (Aminzadeh et al., 2020; Kodidela et al., 2020). Moreover, Dygai et al. (2016); Bathina et al. (2017) stated that, in addition to provoking hyperglycemia in diabetic rats, STZ could enhance increased oxidative stress and proinflammatory cytokines; such as CRP, TNF- $\alpha$, IFN- $\gamma$, hyaluronic acid, IL1- $\beta$, and IL-6; which are positively correlated with measures of insulin deficiency; through inducing edema in the pancreatic insular tissue and its infiltration by inflammatory cells and fibroblasts.

Regarding the selective and progressive autoimmune destruction of the insulin-producing $\beta$-cells in T1DM, it was proved to be a consequence of a targeted lymphocyte attack. In this form of diabetes, $\mathrm{CD} 4^{+}$and $\mathrm{CD} 8^{+} \mathrm{T}$-cells alter their function and secrete large amounts of cytokines such as interleukin-2 (IL-2), IL-8, TGF- $\beta$, MCP-1 and $\gamma$-interferon $(\mathrm{IFN}-\gamma)$ triggering an inflammatory response in the pancreatic islets, which damages $\beta$-cells, resulting in its 


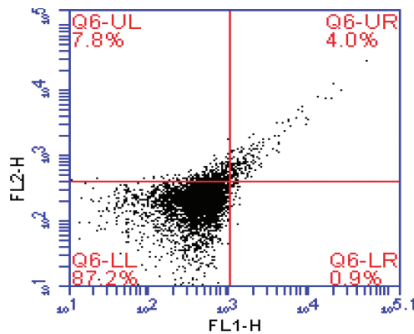

C

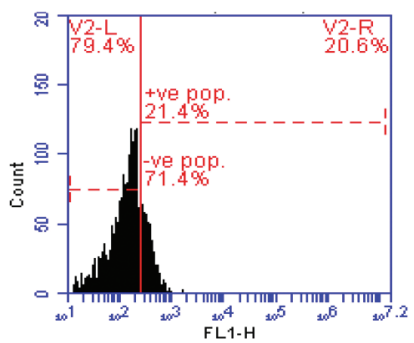

C

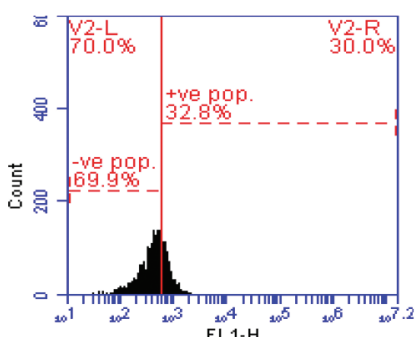

C

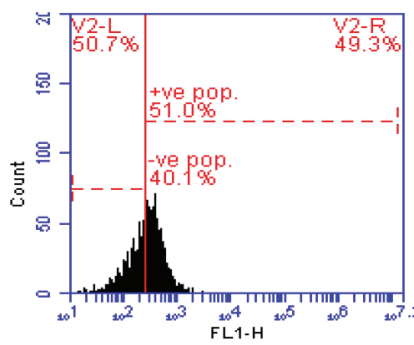

C

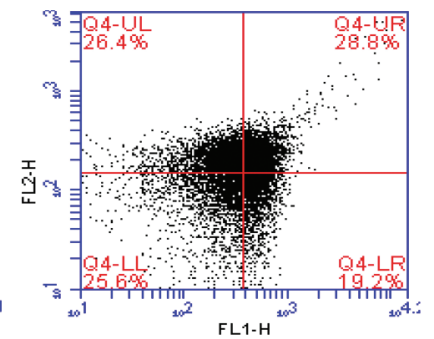

D

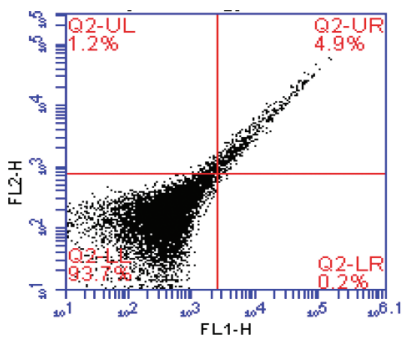

D+AD-MSCs

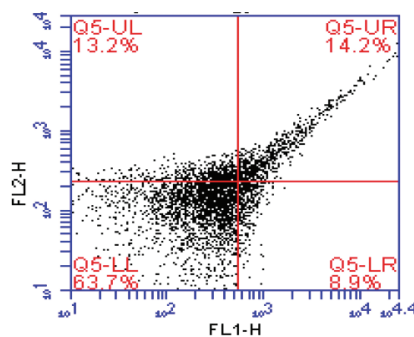

D+BM-MSCs

(A)

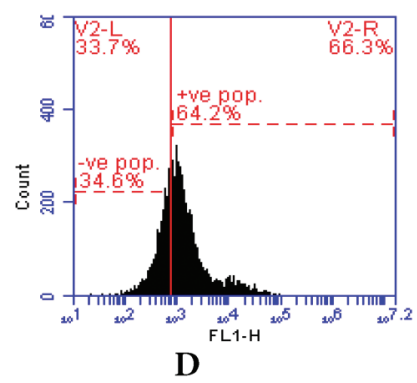

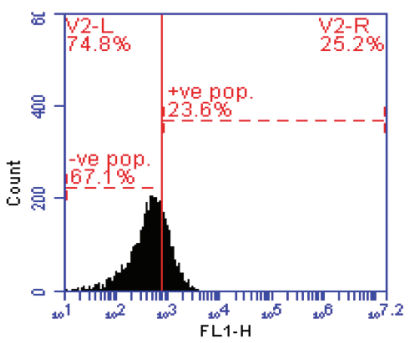

D+AD-MSCs

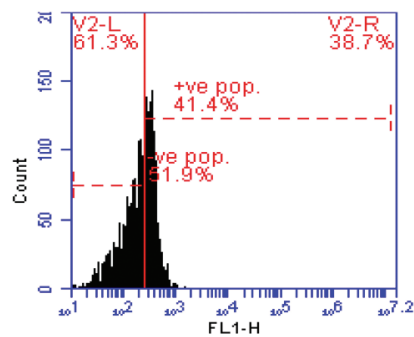

D+BM-MSCs

(B)

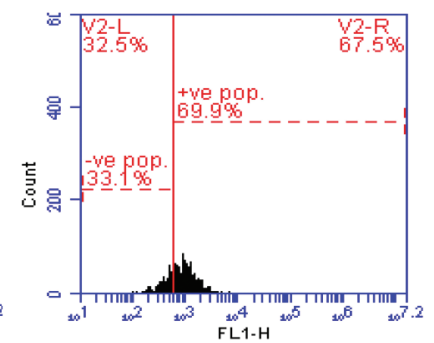

D

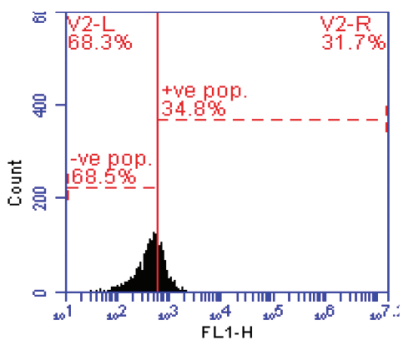

D+AD-MSCs

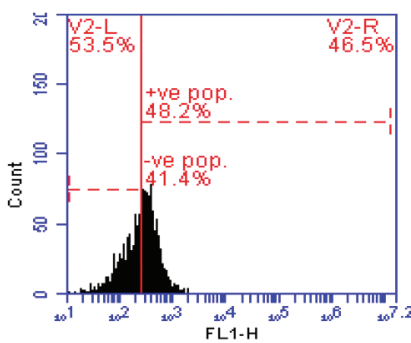

D+BM-MSCs

(C)
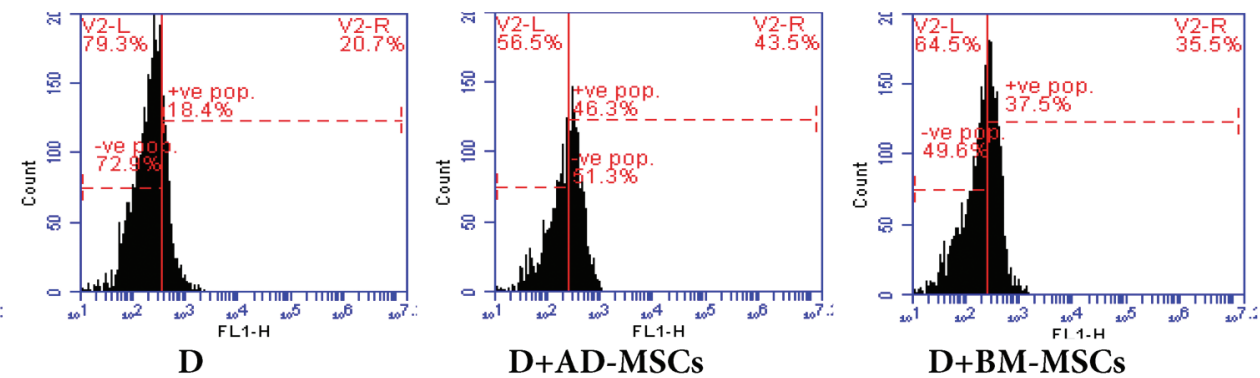

(D)

FIGURE 4. (A-D): Pancreatic annexin V, P53, caspase 3 \& Bcl-2\%, respectively.

Results revealed a marked apoptotic status development in pancreatic cells of diabetic rats; as suggested via the significant increases in many apoptotic markers (annexin V, P53, and caspase $3 \%$ ) accompanied by a significant decrease in both anti-apoptotic marker (Bcl-2\%) and pancreatic viable cells count (G0/G1\%); in regard to control rats. On the contrary, Both MSCs treated groups' tested indicators clearly demonstrated a significant improvement; when compared to the diabetic untreated group.

dysfunction and insulin secretion deficiency (Xv et al., 2017). Moreover, Chen et al. (2017) demonstrated that $\beta$-cells destruction by the autoimmune infiltration is additionally exacerbated by the increased metabolic and glycemic overload; which stimulates TNF- $\alpha$ increased production, which, in turn, causing enhanced production of apoptotic (cleaved caspase-12,9,8 and 3, respectively) ER stress' signaling molecules levels in diabetic rats and apoptosis. Consistent with these findings, another study revealed that
STZ-induced hyperglycemia could initiate pancreatic $\beta$-cells apoptosis in diabetic rats, through elevating annexin, P53, Bax, and caspases-3,8,9 expressions associated with decreased anti-apoptotic Bcl-2 expression (Muruganathan et al., 2017; Aminzadeh et al., 2020).

On the other hand, MSCs have been demonstrated in displaying therapeutic effects in T1DM for their selfrenewable, differentiation potential, and immunosuppressive properties. MSCs from various sources have the potential to 


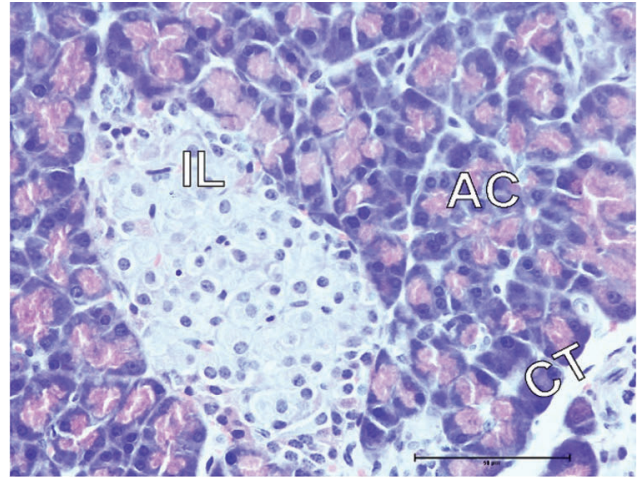

(A)

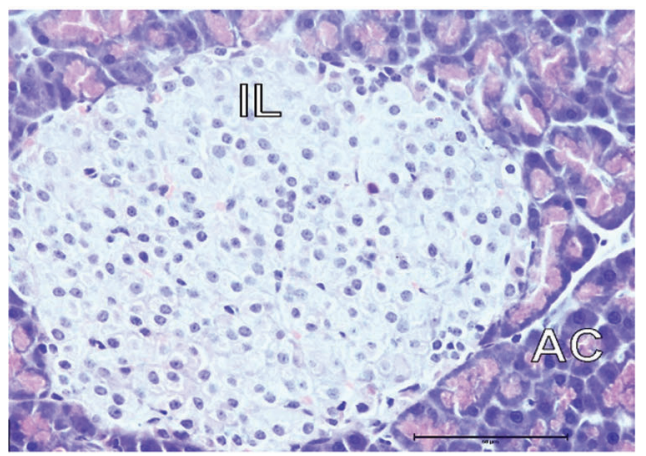

(C)

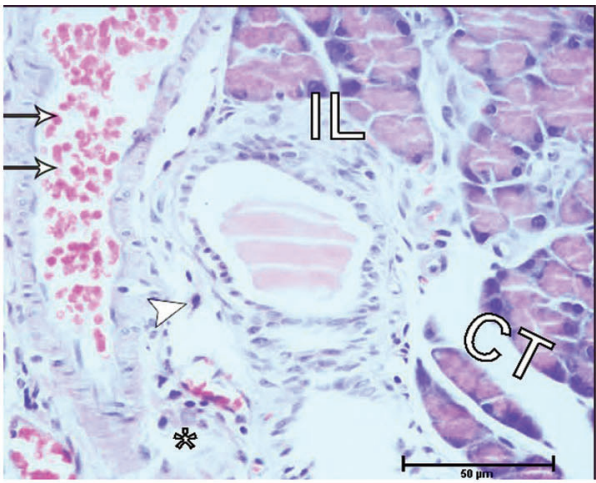

(B)

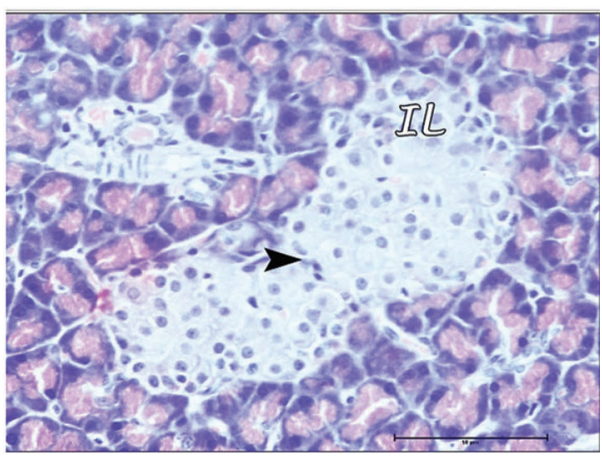

(D)

FIGURE 5. (A-D) demonstrated representative images for pancreatic tissues of control, diabetic, D+AD-MSCs, and D+BM-MSCs groups, respectively.

Fig. 5A showed that pancreatic tissue of control rats exhibited standard structures with no pathological changes illustrated in an intact construction of islets of Langerhans with clear borders, connective tissue septa in between and prominent nuclei within their different cells. In contrast, Fig. 5B clarified that STZ injected animals showed moderate injuries displayed in a reduction in islets' size, congested blood vessels, pyknotic nuclei, in addition to limited vacuolation within the islets referring to the destructive effect of this drug. However, Figs. 5C \& 5D demonstrated that diabetic animals treated with both MSCs types revealed notable amelioration in a varying degree when compared to the STZ treated group and this was presented in the restoration of islets' size, rarely congested blood vessels, the uncommon occurrence of apoptotic nuclei as well. However, AD-MSCs treated diabetic rats displayed superior amelioration when compared to BMMSCs treatment.

\section{TABLE 5}

Pancreatic annexin V, P53, caspase 3 Bcl-2 and viable cells (G0/G1) \%

\begin{tabular}{lllll}
\hline & Control & Diabetic (D) & D+AD-MSCs & D+BM-MSCs \\
\hline Annexin V (\%) & $4.10 \pm 0.25$ & $28.62 \pm 1.52^{\mathbf{a}}$ & $4.95 \pm 0.72^{\mathbf{b}}$ & $14.50 \pm 0.83^{\mathbf{a b c}}$ \\
P53 (\%) & $21.10 \pm 1.33$ & $64.73 \pm 3.63^{\mathbf{a}}$ & $23.52 \pm 1.34^{\mathbf{b}}$ & $41.98 \pm 1.72^{\mathbf{a b c}}$ \\
Caspase 3 (\%) & $32.50 \pm 1.56$ & $70.56 \pm 3.62^{\mathbf{a}}$ & $34.20 \pm 2.23^{\mathbf{b}}$ & $48.50 \pm 2.72^{\mathbf{a b c}}$ \\
Bcl-2 (\%) & $51.00 \pm 2.19$ & $18.30 \pm 0.27^{\mathbf{a}}$ & $46.55 \pm 1.24^{\mathbf{b}}$ & $37.30 \pm 1.62^{\mathbf{a b c}}$ \\
G0/G1 \% & $93.50 \pm 2.23$ & $55.40 \pm 1.37^{\mathbf{a}}$ & $92.50 \pm 2.73^{\mathbf{b}}$ & $75.00 \pm 2.22^{\mathbf{a b c}}$ \\
\hline
\end{tabular}

Note: Values expressed as mean \pm SEM $(n=6){ }^{\mathbf{a}, \mathbf{b}}$ and ${ }^{\mathbf{c}}$ are Significant differences $(P \leq 0.05)$ comparing to control, diabetic and diabetic AD-MSCs treated groups, respectively.

differentiate into IPCs. The differentiation program was controlled by activating key transcription factors such as Pdx-1, Pax4, Pax6, Ngn-3, NeuroD1, and Isl-1. Some of the transcription factors including Isl-1 and Pax-6 were also expressed in AD-MSCs and BM-MSCs, which indicated both are capable to differentiate into the IPCs to cure diabetes (Dave et al., 2014). However, many other reports attributed the obvious hypoglycemic capability of MSCs to their marked antioxidant activity in alleviating the resultant oxidative stress status due to prolonged hyperglycemia. According to
Abdel Fattah et al. (2020); Aminzadeh et al. (2020), administration of MSCs extremely ameliorated the elevated MDA and ROS levels while increasing the mRNA expression levels of many antioxidants; such as GSH, SOD-1 and 3, CAT, GSH-PX-1, 3 and 4, HO-1 and TAC; in STZ-diabetic rats' various tissues including pancreas; relative to diabetic untreated rats. Moreover, MSCs were reported to have a significant impact on the regulation of the immune system, by acting as a potent source of various cytokines and growth factors and manifest multilineage differentiation abilities. Wang et al. (2018) 
demonstrated pancreatic $\beta$ cell mass increased after AD-MSC infusion is associated with less inflammation in the pancreas by reducing TNF- $\alpha$ expression. AD-MSCs also could promote restoration of islet function and increase of islet $\beta$ cells by reducing the rate of apoptosis through decreasing caspase- 3 activity. Meanwhile, the release of paracrine angiogenic factors such as VEGF, IGF-1, HGF, and Vwf can promote islet vascularization and then participate in cell regeneration ( $\mathrm{Hu}$ et al., 2015). Thus, it could be deduced that the mechanisms mediate the protective effects of MSCs most probably, paracrine.

In fact, consistent with our results, a lot of studies highlighted that AD-MSCs have been targeted as potential therapy cells since they have shown some superior functions to BM-MSCs in terms of their immunomodulatory, antiinflammatory, and trophic effects. This excellency might be attributed to certain advantages of AD-MSCs compared with BM-MSCs. First, their easy isolation presents less harvesting difficulty. Second, they have been shown to have a higher differentiative potential. The third advantage involves their much higher immunosuppressive capacity compared to BM-MSCs; since they had supposed not to excite the alloreactivity of incompatible lymphocytes and to suppress the mixed lymphocyte reaction by inducing the expansion of T-regs. Finally, AD-MSCs were found to contribute to a much higher increase in anti-inflammatory cytokines compared to BM-MSCs (Kocan et al., 2017; Wang et al., 2018; Takahashi et al., 2019). Additionally, according to Qi et al. (2019), AD-MSCs attracted more attention due to less harvested inconvenience and ethical issues commonly accompany with bone marrow-derived MSCs (BM-MSCs). In comparison with BM-MSCs, AD-MSCs were characterized by easy accessibility, abundant sources, subcutaneous location, longer incubation time, harvesting with less pain, having senescence later, superiority to maintaining proliferating ability and differentiation potential, and having an approximately threefold increase in immunosuppressive activity. Microarray analysis revealed that $1 \%$ of genes were differentially expressed between AD-MSCs and BM-MSC, which might be the cause of AD-MSCs superiority. Therefore, AD-MSCs may be a better candidate for clinical application in theory.

\section{Conclusion}

Both MSCs types were able to increase the pancreatic $\beta$-cells' antioxidant contents; confirming that suppression of oxidative stress can ameliorate inflammatory damage. However, the injection of $\mathrm{AD}-\mathrm{MSCs}$ was found to be superior to BMMSCs as a pancreatic regenerative tool in overcoming diabetes. AD-MSCs exhibited greater potency in alleviating pancreatic hazards resulting from diabetes induction, over BM-MSCs, as it was most competent for the repression of induced T-cells proliferation; owing to their marked immunosuppressive and anti-apoptotic activities; via inducing the residual $\beta$-cells protection and regeneration while decreasing its destruction in parallel with minimizing their inflammatory and apoptotic status.

Availability of Data and Materials: The datasets generated during and/or analyzed during the current study are available from the corresponding author on reasonable request.
Author Contribution: SGE, HR, and EIE conceived and designed the study. Experiments and lab work were done by SGE, HR, EIE, RMA, MAA, and ES. While data tabulating and acquisition, searching for literature and preparing the first draft of the manuscript were performed by SGE, FA, $\mathrm{AA}$, and EF All authors have read and agreed to the published version of the manuscript.

Ethics Approval: All experimental procedures were approved and performed in accordance with the guidelines of the Animal Ethics Committee of the Faculty of Science, Arish University, North Sinai, Egypt.

Funding Statement: This study was funded by Taif University Researchers Supporting Project No. TURSP-2020/222, Taif University, Taif, Saudi Arabia.

Conflicts of Interest: The authors declare that they have no conflicts of interest to report regarding the present study.

\section{References}

Abdel Fattah S, Waly H, Abou El-Enein B, Kamel A, Labib H (2020). Mesenchymal stem cells versus curcumin in enhancing the alterations in the cerebellar cortex of streptozotocininduced diabetic albino rats. The role of GFAP, PLC and $\alpha$ synuclein. Journal of Chemical Neuroanatomy 109: 101842. DOI 10.1016/j.jchemneu.2020.101842.

Amer MG, Embaby AS, Karam RA, Amer MA (2018). Role of adipose tissue derived stem cells differentiated into insulin producing cells in the treatment of type I diabetes mellitus. Gene 654: 87-94.

Aminzadeh A, Maroof NT, Mehrabani M, Juybari KP, Sharifi AM (2020). Investigating the alterations of oxidative stress status, antioxidant defense mechanisms, MAP kinase and mitochondrial apoptotic pathway in adipose-derived mesenchymal stem cells from STZ diabetic rats. Cell Journal 22: 38-48.

Bagno L, Hatzistergos KE, Balkan W, Hare JM (2018). Mesenchymal stem cell-based therapy for cardiovascular disease: Progress and challenges. Molecular Therapy 26: 1610-1623.

Bathina S, Srinivas N, Das UN (2017). Streptozotocin produces oxidative stress, inflammation and decreases BDNF concentrations to induce apoptosis of RIN5F cells and type 2 diabetes mellitus in Wistar rats. Biochemical and Biophysical Research Communications 486: 406-413.

Bock PP, Karmer R, Paverka M (1980). A simple assay for catalase determination. Cell Biol Monoger 7: 44-74.

Boddu SK, Aurangabadkar G, Kuchay MS (2020). New onset diabetes, type 1 diabetes and COVID-19. Diabetes \& Metabolic Syndrome: Clinical Research \& Reviews 14: 22112217. DOI 10.1016/j.dsx.2020.11.012.

Boháčová P, Holáň V (2018). Mesenchymal stem cells and type 1 diabetes treatment. Vnitřní lékařství 64: 725-728. DOI 10.36290/vnl.2018.099.

Chandra V, Swetha G, Phadnis S, Nair P, Bhonde R (2009). Generation of pancreatic hormone-expressing islet-like cell aggregates from murine adipose tissue-derived stem cells. Stem Cells 27(8): 1941-1953.

Chandravanshi B, Bhonde R (2017). Shielding engineered islets with mesenchymal stem cells enhance survival under hypoxia. Journal of Cellular Biochemistry 118: 2672-2683. DOI 10.1002/jcb.25885. 
Chen C, Cohrs CM, Stertmann J, Speie S (2017). Human beta cell mass and function in diabetes: Recent advances in knowledge and technologies to understand disease pathogenesis. Molecular Metabolism 6: 943-957. DOI 10.1016/j.molmet.2017.06.019.

Chen TS, Lai PF, Kuo CH, Day CH, Chen RJ et al. (2020). Resveratrol enhances therapeutic effect on pancreatic regeneration in diabetes mellitus rats receiving autologous transplantation of adipose-derived stem cells. Chinese Journal of Physiology 63: 122-127. DOI 10.4103/CJP.CJP_3_20.

Dave SD, Vanikar AV, Trivedi HL (2014). In-vitro generation of human adipose tissue derived insulin secreting cells: Up-regulation of Pax-6, Ipf-1 and Isl-1. Cytotechnology 66: 299-307. DOI 10.1007/s10616-013-9573-3.

Dean PN, Jett JH (1974). Mathematical analysis of DNA distributions derived from flow microfluorometry. Journal of Cell Biology 60: 523-527. DOI 10.1083/jcb.60.2.523.

Dygai AM, Skurikhin EG, Pershina OV, Kravtsov VY (2016). Role of hematopoietic stem cells in inflammation of the pancreas during diabetes mellitus. Bulletin of Experimental Biology and Medicine 160: 474-479. DOI 10.1007/s10517-016-3200-1.

El-Kholy WM, Hussein RH, Khalil DY (2018). Antioxidant and antiinflammatory therapeutic roles of BM-Mscs in enhancing pancreatic auto-immunity and apoptotic status in TIDM. American Journal of Science 14: 1-12.

El-Sawah SG, Nabil A, Rashwan H, Khalil DY, Khalil RY (2020). BMMSCS' immunomodulatory, anti-inflammatory, anti-apoptotic and antioxidant capacity roles in Modulating the altered tissues' oxidative stress status in STZ-diabetic rats: in comparison to the standard insulin treatment. International Journal of Advanced Research 8: 591-617. DOI 10.21474/IJAR01/11532.

Erendor F, EmreEksi E, Sahin EO, Balci MK, Griffith TS et al. (2021). Lentivirus mediated pancreatic beta-cell-specific insulin gene therapy for STZ-induced diabetes. Molecular Therapy 29: 149-161. DOI 10.1016/j.ymthe.2020.10.025.

Flier J, Kahn C, Jarrett D, Roth J (1976). Characterization of antibodies to the insulin receptor: A cause of insulinresistant diabetes in man. Journal of Clinical Investigation 58: 1442-1449. DOI 10.1172/JCI108600.

Gabr MM, Zakaria MM, Refaie AF, Abdel-Rahman EA, Reda AM et al. (2017). From human mesenchymal stem cells to insulin-producing cells: Comparison between bone marrow- and adipose tissue-derived cells. BioMed Research International 8: 1-9. DOI 10.1155/2017/3854232.

Gibbons CH, Freeman R (2020). Treatment-induced neuropathy of diabetes: An acute, iatrogenic complication of diabetes. Brain 138: 43-52. DOI 10.1093/brain/awu307.

Gonen B, Rubenstein AH (1978). Estimation of glycosylated hemoglobin. Diabetologia 15: 1-8. DOI 10.1007/BF01219319.

Habig H, Pabst J, Jakoby B (1974). Glutathione-S-transferase the first enzyme step in mercapturic acid formation. Journal of Biological Chemistry 1: 7139-7150.

Hamza AH, Al-Bishri WM, Damiati LA, Ahmed HH (2017). Mesenchymal stem cells: A future experimental exploration for recession of diabetic nephropathy. Renal Failure 39: 6776. DOI 10.1080/0886022X.2016.1244080.

Hu J, Fu Z, Chen Y, Tang N, Wang L et al. (2015). Effects of autologous adipose-derived stem cell infusion on type 2 diabetic rats. Endocrine Journal 62: 339-352. DOI 10.1507/ endocrj.EJ14-0584.

Jamshidi M, Ziamajidi N, Khodadadi I, Dehghan A, Kalantarian G (2018). The effect of insulin-loaded trimethylchitosan nanoparticles on rats with diabetes type I. Biomedicine \& Pharmacotherapy 97: 729-735. DOI 10.1016/j.biopha.2017.10.097.

Kocan B, Maziarz A, Tabarkiewicz J, Ochiya T, Banaś-Ząbczyk A (2017). Trophic activity and phenotype of adipose tissuederived mesenchymal stem cells as a background of their regenerative potential. Stem Cells International 2017: 1-13. DOI 10.1155/2017/1653254.

Kodidela S, BegumShaik F, Chinta V, AliMohammad S, Pasala C et al. (2020). Possible ameliorative role of green tea on chronic alcohol mediated renal toxicity of STZ -induced diabetic rats. Clinical Nutrition Experimental 34: 1-25. DOI 10.1016/j.yclnex.2020.09.001.

Kono TM, Sims EK, Moss DR, Yamamoto W, Ahn G et al. (2014). Human adipose-derived stromal/stem cells protect against STZ-induced hyperglycemia: Analysis of hASC-derived paracrine effectors. Stem Cells 32: 1831-1842. DOI 10.1002/ stem. 1676 .

Koracevic D, Koracevic G, Djordjevic V, Andrejevic S, Cosic V (2001). Method for the measurement of antioxidant activity in human fluids. Journal of Clinical Pathology 54: 356-361. DOI 10.1136/jcp.54.5.356.

Laddha AP, Kulkarni YA (2019). Tannins and vascular complications of Diabetes: An update. Phytomedicine 56: 229-245. DOI 10.1016/j.phymed.2018.10.026.

Muruganathan U, Srinivasan S, Vinothkumar V (2017). Antidiabetogenic efficiency of menthol, improves glucose homeostasis and attenuates pancreatic $\beta$-cell apoptosis in streptozotocin-nicotinamide induced experimental rats through ameliorating glucose metabolic enzymes. Biomedicine \& Pharmacotherapy 92: 229-239. DOI 10.1016/j.biopha.2017.05.068.

Nishikimi M, Roa NA, Yagi K (1972). Measurement of superoxide dismutase. Biochemical and Biophysical Research Communications 46: 849-854. DOI 10.1016/S0006291X(72)80218-3.

Ohkawa H, Wakatsuki A, Kaneda C (1982). Assay for lipid peroxides in animals tissues by thiobarbituric acid reaction. Analytical Biochemistry 95: 351-358. DOI 10.1016/0003-2697(79) 90738-3.

Paul S, Ali A, Katare R (2020). Molecular complexities underlying the vascular complications of diabetes mellitus: A comprehensive review. Journal of Diabetes and its Complications 34: 107613. DOI 10.1016/j.jdiacomp.2020.107613.

Peng B, Dubey NK, Mishra VK, Tsai F, Dubey R et al. (2018). Addressing stem cell therapeutic approaches in pathobiology of diabetes and its complications. Journal of Diabetes Research 2018: 1-16. DOI 10.1155/2018/7806435.

Prins HK, Loose JA (1969). Glutathione in biochemical methods in red cell genetics, vol. 1, pp. 126-129. London: Academic Press.

Qi K, Li N, Zhang Z, Melino G (2017). Tissue regeneration: The crosstalk between mesenchymal stem cells and immune response. Cellular Immunology 326: 86-93.

Qi Y, Ma J, Li S, Liu W (2019). Applicability of adipose-derived mesenchymal stem cells in treatment of patients with type 2 diabetes. Stem Cell Research \& Therapy 10: 2515. DOI 10.1186/s13287-019-1362-2.

Samaha MM, Said E, Salim HA (2020). Modulatory role of imatinib mesylate on pancreatic $\beta$-cells' secretory functions in an STZ rat model of diabetes mellitus. Chemico-Biological Interactions 328: 109197. DOI 10.1016/j.cbi.2020.109197.

Shree N, Bhonde RR (2017). Conditioned media from adipose tissue derived mesenchymal stem cells reverse insulin resistance in 
cellular models. Journal of Cellular Biochemistry 118: 20372043. DOI 10.1002/jcb.25777.

Sordia V, Pellegrinia S, Kramperab M, Pantèh G, Piemonti L (2017). Stem cells to restore insulin production and cure diabetes. Nutrition, Metabolism and Cardiovascular Diseases 27: 583-600. DOI 10.1016/j.numecd.2017.02.004.

Suvarna SK, Layton C, Bancroft JD (2012). Bancroft's theory and practice of histological techniques. 7th ed. Churchill Livingstone. (1 online resource).

Takahashi H, Sakata N, Yoshimatsu G, Hasegawa S, Kodama S (2019). Regenerative and transplantation medicine: Cellular therapy using adipose tissue-derived mesenchymal stromal cells for type 1 diabetes mellitus. Journal of Clinical Medicine 8: 249. DOI 10.3390/jcm8020249.

Thakkar UG, Trivedi HL, Vanikar AV, Dave SD (2015). Insulinsecreting adipose-derived mesenchymal stromal cells with bone marrow-derived hematopoietic stem cells from autologous and allogenic sources for type 1 diabetes mellitus. Cytotherapy 17: 940-947. DOI 10.1016/j.jcyt.2015.03.608.

Thakkar UG, Vanikar A, Trivedi HL (2017). Should we practice stem cell therapy for type 1 diabetes mellitus as precision medicine? Cytotherapy 19: 574-576. DOI 10.1016/j.jcyt.2017.02.001.

Tribukait B, Moberger G, Zetterberg A (1975). Methodological aspects of rapid-flow cytofluorometry for DNA analysis of human urinary bladder cells. European Press 1: 50-60.

Trinder P (1969). Determination of glucose in blood using glucose oxidase with an alternative oxygen acceptor. Annals of Clinical Biochemistry: International Journal of Laboratory Medicine 6: 24-27. DOI 10.1177/000456326900600108.

Ullah M, Liu DD, Thakor AS (2019). Mesenchymal stromal cell homing. Mechanisms and Strategies for Improvement. iScience 15: 421-438.
Vaishnavi C (1996). Quantitative determination of CRP. Immunology \& Infectious Diseases J 6: 139-144.

Wang M, Song L, Strange C, Dong X, Wang H (2018). Therapeutic effects of adipose stem cells from diabetic mice for the treatment of type 2 diabetes. Molecular Therapy 26: 19211930. DOI 10.1016/j.ymthe.2018.06.013.

Williams DM, Nawaz A, Evans M (2020). Drug therapy in obesity: A review of current and emerging treatments. Diabetes Therapy 11: 1199-1216. DOI 10.1007/s13300-020-00816-y.

Xie M, Hao HJ, Cheng Y, Xie ZY, Yin YQ et al. (2017). Adipose-derived mesenchymal stem cells ameliorate hyperglycemia through regulating hepatic glucose metabolism in type 2 diabetic rats. Biochemical and Biophysical Research Communications 483: 435-441. DOI 10.1016/j.bbrc.2016.12.125.

Xv J, Ming Q, Wang X, Zhang W, Li Z et al. (2017). Mesenchymal stem cells moderate immune response of type 1 diabetes. Cell and Tissue Research 368: 239-248. DOI 10.1007/ s00441-016-2499-2.

Young DS (2001). Effects of disease on clinical laboratory tests. Clinical Chemistry 4: 17-18

Zang L, Hao H, Liu J, Li Y, Han W et al. (2017). Mesenchymal stem cell therapy in type II diabetes mellitus. Diabetology Metabolic Syndrome 9: 1-11.

Zhong Z, Tang R, Gong S, Li G, Li X et al. (2020). The remission phase in type 1 diabetes: Changing epidemiology, definitions, and emerging immuno-metabolic mechanisms. Diabetes/Metabolism Research and Reviews 36: 332. DOI 10.1002/dmrr.3207.

Zhou J, Zhang Z, Qian G (2016). Mesenchymal stem cells to treat diabetic neuropathy: A long and strenuous way from bench to the clinic. Cell Death Discovery 2: 817. DOI 10.1038/ cddiscovery.2016.55. 